\title{
Novos paradigmas nos saberes docentes da Educação a Distância
}

\author{
Regina Trilho Otero Xavier - trilhote@ucpel.tche.br - UCPel/CEAD \\ João Alberto da Silva - joao.alberto@ufrgs.br - UFRGS/NEEGE
}

Resumo: Este trabalho trata da construção do conhecimento-solidariedade em EAD. A partir dos referenciais de Boaventura Santos, procura-se compreender o conhecimentosolidariedade, bem como os valores e saberes que favorecem seu desenvolvimento em ações pedagógicas de professores em EAD. Os dados indicam que, no Estudo de Caso realizado, os professores identificam positivamente a prática construida na modalidade a distância, mas encontram dificuldades para compreender e trabalhar com valores em suas aulas. As conclusões evidenciam que o conhecimento-solidariedade, na modalidade EAD, está fortemente vinculado aos diversos saberes docentes; que se trata de um saber construído progressivamente, em experiências permeadas por respeito mútuo, reciprocidade e empatia, tendo a cooperação como principal estratégia.

Palavras-chave: educação a distância, conhecimento-solidariedade, pedagogia universitária.

\section{New paradigms in teacher knowledge of distance education}

Abstract: This work reports a research that investigates the construction of solidarityknowledge in Distance Learning. From the references of Boaventura Santos we try to understand what solidarity-knowledge is about, as well as the values and knowledge that favor its development in pedagogical actions of teachers and students in Distance Learning. The data indicate that, in the Case Study conducted, the teachers identify positively the practice carried out in the Distance Learning, but they are difficult to understand and work with values in their lessons. The conclusions show that the solidarity-knowledge in the Distance Learning modality is strongly linked to the ethical, technical, pedagogical, communicative and managing knowledge; that this is about an acquirement progressively constructed in experiences permeated by mutual respect, reciprocity, and empathy, having the cooperation as the main strategy.

Key words: distance learning, solidarity-knowledge, university pedagogy.

\section{Introdução}

Quais os saberes a serem mobilizados para se preparar uma aula? Para alguns professores a resposta é óbvia: são aqueles que compõem os conteúdos da disciplina, é claro! Se continuarmos perguntando, é possível que esses professores mantenham-se firmes na sua resposta, julgando-a a única possível. Na verdade, todo o ser humano sofre influências de sua história de vida, evidenciando-as em suas condutas. Os valores mais fortes falarão mais alto, se não tiverem sido abafados. Assim, quando o professor prepara a sua aula, está mobilizando, também, conhecimentos sobre suas próprias experiências de sucesso ou fracasso e, sobretudo, sua concepção de mundo, de conhecimento e do outro. Isto significa que a aula será preparada de acordo com o "valor" que o professor atribui ao seu aluno e de sua própria concepção de ensino e de aprendizagem. O mesmo acontecerá com a qualidade das relações estabelecidas com seus alunos, com o tipo de atividades que irá propor, com o controle da presença e com o modelo de avaliação que adotará.

Nosso questionamento se concentra em como são construídos os outros conhecimentos que o professor mobiliza na sua ação docente? Em se tratando de EAD, que saberes são necessários acrescentar ou/e modificar para conseguir fazer uso das potencialidades que os recursos dos Ambientes Virtuais de Aprendizagem (AVA) oferecem? E ainda, se a proposta pedagógica incluir o conhecimento-solidariedade como 
norteador das ações docentes em EAD, como deverá ser o desempenho deste professor?

Procurando responder estas questões, considera-se que todo o período de formação, que toda a vida do professor, estão, de alguma forma, refletidas na sua ação docente. Logo, é importante reconhecer a influência de determinados paradigmas nas ações desenvolvidas, bem como reconhecer que uma concepção de conhecimento e uma teoria moral subjazem as suas ações. Desta forma, investigamos quais são os pressupostos levados em conta por professores que lecionam em disciplinas a distância na Universidade Católica de Pelotas - UCPel - na organização de sua prática educativa, haja vista que a instituição adota a perspectiva epistemológica do conhecimentosolidariedade. Dentre os diversos saberes necessários para na EAD destacaremos os elementos a seguir

\section{Saberes docentes}

1) O Conhecimento Solidariedade

De acordo com Santos (2002), os paradigmas nascem, desenvolvem-se e morrem. Assim, a partir do momento em que as grandes promessas de progresso para a humanidade não aconteceram e graves devastações do meio-ambiente passaram a ocorrer com maior frequiência e amplitude, não foi mais possível deixar de perceber o nascimento de um outro modelo: o paradigma emergente, também denominado paradigma da solidariedade.

Este paradigma baseia-se em uma nova maneira de fazer ciência, no sentido de um ato humano, preocupada em proporcionar para a humanidade, como um todo, "um conhecimento prudente para uma vida decente". Santos (2002) acredita que se está vivendo a crise final do paradigma dominante e propõe que se faça uma crítica radical deste modelo. Os problemas sociais, intensamente ampliados na atualidade, tiveram origem na concepção de ciência que, há vários anos, domina o mundo. Deste modo, para que ocorra a transição social, é necessário que se dê início à crítica epistemológica: "todo conhecimento crítico deve começar pela crítica do conhecimento" (Santos, 2002, p.29).

Neste texto, utilizaremos o termo "solidariedade" com o sentido de se empenhar pelo bem comum. Esta forma de concebê-la aproxima-se muito da definição de generosidade. Logo, pode-se presumir que solidariedade tem a ver com a maneira de se enxergar o mundo, a vida e, principalmente, com a forma de perceber e agir em relação com o outro. Esse reconhecimento do outro, com suas diferenças e singularidades, pressupõe uma constante descentração de si mesmo e de suas certezas. Sobretudo, pressupõe o reconhecimento da interdependência e da coesão social como fatos fundamentais, tanto para as sociedades, quanto para o indivíduo.

2) Saberes Docentes da Educação Presencial e a Distância

A ação docente voltada para o "conhecimento-solidariedade" encontra algumas barreiras que precisam ser transpostas. Muitas delas decorrem do paradigma da ciência moderna, que tem influenciado, fortemente, os modos de pensar e agir em todas as áreas. Neste sentido, o entendimento e a conscientização de tal domínio constituem-se em pontos importantes para o professor que deseja direcionar suas ações na perspectiva da solidariedade. Conhecer as características e as "razões de ser" do paradigma dominante e do emergente pode se constituir na possibilidade de aproximação de um desempenho profissional mais solidário. Moraes (1996) também utiliza o termo "paradigma emergente" para caracterizar uma nova forma de pensar a Educação. De acordo com a autora, o paradigma educacional emergente é:

- construtivista: conhecimento sempre em construção;

- interacionista: o conhecimento ocorre na interação com o outro; 
- sócio-cultural: o conhecimento acontece a partir do diálogo do homem consigo mesmo e com o mundo que o cerca;

- transcendente: expansão da consciência do outro, aumento dos sentimentos de humildade, fraternidade e solidariedade.

Neste sentido, Cunha, mesmo reconhecendo que "ainda é muito forte a influência do paradigma da ciência moderna - calcada na compreensão positivista sobre as concepções que presidem a prática pedagógica" (1998, p.109), relata que existem algumas condições facilitadoras para motivar os professores a viverem experiências na perspectiva da produção de conhecimento. São elas:

- a existência de uma estrutura de apoio ligada a um projeto pedagógico;

- o fato de estar trabalhando em grupo;

- a possibilidade de experiência planejada de forma interdisciplinar;

- o entendimento de que mudança é processo.

Os professores que se propõem a trabalhar na perspectiva de produção de conhecimento, se comparados com os que agem de acordo com o paradigma da transmissão, para Cunha (1998), apresentam diferenças em algumas de suas concepções, compromissos e métodos de trabalho. Outro aspecto enfocado, como condição de reforço a práticas inovadoras, diz respeito aos questionamentos do professor quanto ao seu modo de ensinar, o que os leva a buscar novos conhecimentos para melhorar sua atuação. No mesmo sentido, a compreensão do professor quanto ao protagonismo do aluno no seu processo de aprendizagem, pode proporcionar a valorização da produção dos estudantes, favorecendo-os neste sentido.

3) Os saberes técnicos e de gestão em EAD

Os saberes técnicos em EAD referem-se aos conhecimentos sobre o uso das tecnologias da informação e da comunicação (TIC) e dos AVA que os docentes terão a sua disposição. Em geral, os recursos mais utilizados dizem respeito aos processadores de texto, softwares de apresentação, planilhas eletrônicas e uso de vídeos. Os maiores problemas que surgem, relacionados ao domínio destes recursos, originam-se do medo que os professores sentem de cometer erros ao tentar usá-los, à falta de paciência para aprender, do esquecimento das etapas necessárias para atingir o fim desejado, do pouco tempo que dispõem ou, ainda, à falta de equipamentos, softwares e/ou pessoal qualificado para ensiná-los.

Seria ideal que, antes de se tornarem professores na modalidade a distância, os docentes freqüentassem um ou mais cursos preparatórios. A partir de então, passariam a conhecer melhor o AVA utilizado pela instituição, os recursos disponíveis e a maneira de usá-los, podendo, ainda, vivenciar a situação de alunos a distância e formar uma base para suas ações docentes. Essa vivência no ambiente virtual possivelmente teria um efeito de virtualização, no sentido de Levy (1997). Professores, quando atuam como alunos e/ou como docentes em EAD, tendem a problematizar a relação educativa, presencial e virtual. Os questionamentos que surgem podem ser dinamizadores de atos de criação, podendo, assim, suscitar condições de ruptura epistemológica, conforme Cunha (1996, 1998, 2005).

Além disso, os AVA proporcionam várias ferramentas para a comunicação com os alunos ou aluno-aluno, disponibilização e tratamento de conteúdo, acompanhamento do processo de aprendizagem, registro de sentimentos pessoais, avaliação e controle de presença no ambiente. Estas ferramentas permitem o envio de arquivos produzidos em vários tipos de programas, demandando tempo para aprender a utilizar os recursos e ferramentas que o professor dispõe para utilizá-los na criação e acompanhamento das aulas. Logo, a EAD exige do professor, além do conhecimento dos recursos informáticos e de suas características e potencialidades, um outro saber específico desta modalidade de educação, que é a gestão desses recursos informáticos e do tempo que o professor dispõe para utilizá-los. 
4) Os saberes pedagógicos e comunicacionais em EAD

O professor a distância, ao desejar fazer uso de potencialidades dos recursos existentes em EAD deverá possuir um perfil que lhe permita: entendimento da existência de uma lógica comunicacional aberta e flexível no AVA e capacidade de utilizá-la de forma positiva no grupo; compreensão e uso de interatividade; capacidade de pensamento complexo e de uso das características das Comunidades Virtuais de Aprendizagem (CVA), que se formam nos AVA.

Outro aspecto específico da modalidade EAD refere-se à capacidade de concretude e resiliência das informações, isto é, todos os conteúdos, inclusive o conteúdo das trocas, ficam gravados no ambiente. $\mathrm{O}$ aluno não necessita usar de sua capacidade de abstração para lembrar e trabalhar com eles. Pode-se retornar os conteúdos tantas vezes quantas forem necessárias, ou transformá-los mentalmente em outro espaço digital.

Como a aprendizagem ocorre por aproximações, e como cada vez que o sujeito se volta para o objeto de aprendizagem pode apreender caracteres que, anteriormente, não havia apreendido, a concretude e a resiliência das informações em um ambiente de EAD constituem-se em especificidades da modalidade, que podem significar vantagens para o aluno. As capacidades de abstração e da memória ficam mais liberadas e, deixando fora esta dependência, garante-se a exatidão das informações, sem os "ajeitamentos" que a mente opera.

No que diz respeito à lógica de comunicação, os recursos existentes na modalidade EAD dão ao professor a possibilidade de deixar de lado a lógica linear de comunicação, comum na maioria das salas de aula, onde um fala e os outros escutam. Hoje é possível, a qualquer hora e em qualquer lugar, a comunicação generalizada entre muitas pessoas, bem diferente do que acontece na aula presencial. Na EAD o pensamento pode ser expresso muitas vezes, de forma espontânea, sem as travas da auto-censura. Alunos introspectivos sentem-se à vontade em suas manifestações, contribuindo para o enriquecimento do assunto em foco, o que dificilmente fariam de forma presencial.

O pensamento linear, característico da lógica de comunicação tradicional, prejudica a interatividade. Somente o pensamento complexo, aberto e flexível permite ao professor agir de acordo com esta nova lógica de comunicação, que se constitui, também, numa "porta aberta" para o conhecimento-solidariedade. A inspiração do paradigma da solidariedade está relacionada com a complexidade. O pensamento linear, cartesiano, não é suficiente para dar conta da complexidade do mundo e de cada ser humano, de forma especial. O pensamento complexo atua como um ligador que supera as dicotomias e articula "saberes" visto como separados. De acordo com Morin (2003), o movimento, a imprecisão, a incompletude, a união da complexidade e da simplificação, da ordem e da desordem, da subjetividade e da objetividade, são características do pensamento complexo. Porém, o autor ressalta que este pensamento que desconhece de antemão as respostas, não é um pensamento inconseqüente, pelo contrário: ele se guia por princípios de responsabilidade em relação a si mesmo e para com o outro e pela consciência da interligação de todos os fatores, o que deixa tudo e todos com imensa responsabilidade pelo futuro da humanidade. A compreensão da complexidade existente é, também, a compreensão de que o todo está na parte assim como a parte está no todo. Logo, o pensamento complexo se inspira na busca da plenitude e completude dos indivíduos, permitindo aos homens cumprirem sua missão terrestre de salvaguardar a humanidade e darem continuidade ao processo de hominização.

O pensamento de Santos (2002), relativo à atitude coerente com o paradigma da solidariedade, inclui o que ele chama de uma nova subjetividade: a subjetividade da fronteira. Considerando que estamos vivendo novos tempos e que, para caminhar na perspectiva do conhecimento-solidariedade teremos que trilhar caminhos totalmente desconhecidos, que fogem aos padrões anteriores fornecidos pelo paradigma da ciência 
moderna, o autor diz que o sentimento ideal é semelhante àquele que os pioneiros tiveram ao desbravar terras desconhecidas, ao buscar as "terras de ninguém".

Agir na fronteira, sem mapas referenciais, exige uma nova forma de sociabilidade, em que coexistem "hierarquias fracas, pluralidade de poderes e ordens jurídicas, fluidez das relações sociais, promiscuidade entre estranhos e íntimos, misturas de heranças e invenções" (Santos, 2002, p.347). Essa subjetividade de fronteira, de que nos fala o autor, é a subjetividade que favorece as ações em EAD na perspectiva do conhecimentosolidariedade. Cunha (2001) relata as tendências teóricas de revalorização da dimensão da subjetividade, em oposição à objetividade imposta pelo paradigma da ciência moderna. A autora fala da preocupação atual em compreender como acontece a produção de significados e de como esses significados estão vinculados aos processos cognitivos e emocionais dos aprendizes. Nesta perspectiva, saber como o aluno se vê e qual sua visão de futuro poderá ser o ponto de partida para fazer com que o processo educativo seja um momento de entusiasmo e prazer.

Sendo assim, ao recuperar a importância do reconhecimento das subjetividades, os docentes estarão caminhando na direção de Santos (2002), quando menciona que todo conhecimento é auto-conhecimento. A ação docente na perspectiva do conhecimentosolidariedade reconhece, também, que as intersubjetividades dependem da concepção do próximo numa teia de reciprocidade, isto é, esta nova subjetividade é muito mais dependente da reciprocidade do que da identidade, enfatizando a importância dos saberes éticos.

\section{Métodos e Instrumentos de Pesquisa}

Este trabalho consiste em uma pesquisa quanti-qualitativa em que se faz uso de diversas fontes de evidência (André e Lüdke, 1986). A questão central que norteia este estudo é relacionada aos saberes que os professores consideram necessários para a EAD, tendo por base o conhecimento-solidariedade. Para respondê-la, foram acrescidas as seguintes questões preliminares:

1) Que condições pedagógicas, técnicas e éticas favorecem o desenvolvimento do conhecimento-solidariedade na modalidade de EAD?

2) Que saberes são mobilizados para desenvolver uma experiência em EAD, na perspectiva do conhecimento-solidariedade?

Para investigar como são percebidas ações pedagógicas na perspectiva do conhecimento-solidariedade, a pesquisa envolveu os professores e os alunos das cinco turmas na modalidade EAD da UCPel, oferecidas no primeiro semestre de 2007. Os docentes e os estudantes responderam a um mesmo questionário, com a finalidade investigar a visão dos professores sobre sua prática, bem como verificar se os alunos estão de acordo com essas percepções.

Através do sistema informatizado da UCPel foi enviado um questionário para o endereço eletrônico de todos os alunos que haviam se matriculado nas disciplinas a distância, num total de 178 pessoas. Responderam ao questionário 47 sujeitos, representando um retorno de 26,4\%. Os cinco professores foram contatados diretamente. As entrevistas envolviam dados quantitativos e qualitativos. As questões de 1 a 10 eram fechadas, enquanto as demais eram abertas. Inicialmente, as respostas foram trabalhadas conforme as possíveis categorias apresentadas no quadro a seguir.

Quadro 1 - Relação das questões do instrumento e categorias iniciais

\begin{tabular}{|l|c|}
\hline \multicolumn{1}{|c|}{ Questões } & Categorias inicialmente projetadas \\
\hline $\begin{array}{l}\text { 1) Na apresentação dos conteúdos, incentiva(o) os alunos a pesquisarem e contribuírem } \\
\text { com a turma? }\end{array}$ & Protagonismo - Cooperação \\
\hline 2) Relaciona(o) os assuntos abordados de acordo com a realidade dos alunos? & Objetividade \\
\hline 3) Diversifica(o) as atividades desenvolvidas? & Criatividade \\
\hline $\begin{array}{l}\text { 4) Nos posicionamentos sobre os conteúdos que estão sendo trabalhados, incentiva(o) a } \\
\text { discussão coletiva? }\end{array}$ & $\begin{array}{c}\text { Interação Comunicacional - } \\
\text { Protagonismo - Subjetividades }\end{array}$ \\
\hline
\end{tabular}




\begin{tabular}{|l|c|}
\hline $\begin{array}{c}\text { 5) Incentiva(o) atividades que promovam a expressão de aspectos pessoais entre os } \\
\text { participantes (por exemplo: registro de expectativas e sentimentos)? }\end{array}$ & Subjetividades - Interação \\
\hline $\begin{array}{c}\text { 6) Utiliza(o) formas de avaliação que permitem verificar capacidade de argumentação e } \\
\text { de fundamentação? }\end{array}$ & $\begin{array}{c}\text { Interação Comunicacional - } \\
\text { Protagonismo }\end{array}$ \\
\hline $\begin{array}{l}\text { 7) Demonstra(o) preocupação com a opinião dos alunos? } \\
\text { Comunicacional - Respeito Ativo }\end{array}$ & Cooperação - Respeito Ativo \\
\hline $\begin{array}{l}\text { 8) Nas atividades desenvolvidas, incentiva(o) integração e ajuda mútua entre os } \\
\text { participantes? }\end{array}$ & Respeito Mútuo - Respeito Ativo \\
\hline 9) Demonstra(o) preocupação com o desenvolvimento de respeito mútuo entre todos? & Responsabilidade -Consciência \\
\hline 10) Demonstra(o) preocupação com os valores que está(ou) passando para os alunos? & $\begin{array}{c}\text { Condições de } \\
\text { satisfações/insatisfações }\end{array}$ \\
\hline $\begin{array}{l}\text { 11) Se você for ser novamente aluno/professor na modalidade EAD o que você } \\
\text { mudaria? }\end{array}$ & $\begin{array}{c}\text { Condições de } \\
\text { satisfações/insatisfações }\end{array}$ \\
\hline $\begin{array}{l}\text { 12) Nessa experiência diferenciada de ensino aprendizagem, como você se sentiu como } \\
\text { aluno/professor? }\end{array}$ & Condições de aprendizagens \\
\hline 13) Quais foram suas principais aprendizagens? & Condições de dificuldades \\
\hline 14) Quais foram suas maiores dificuldades? & Condições de virtualização \\
& Ruptura \\
\hline $\begin{array}{l}\text { 15) Existem aprendizagens realizadas a partir dessa experiência na modalidade EAD que } \\
\text { poderão modificar sua atuação como aluno/professor nas aulas presenciais? }\end{array}$ & éticos) \\
\hline $\begin{array}{l}\text { 16) Você acredita que ações de solidariedade na modalidade EAD podem ser } \\
\text { desenvolvidas? Como? }\end{array}$ & Condições de Solidariedade (aspectos \\
\hline
\end{tabular}

\section{Resultados e discussão}

Diante dos saberes (educacionais, técnicos, comunicacionais, etc.) anteriormente mencionados, investigamos os pressupostos que os próprios docentes analisavam como importantes em sua prática. Os dados, colhidos através das respostas às questões objetivas do instrumento, foram tratados com auxílio dos programas Statistical Package for Social Science (SPSS), STATISTICA e Excel. Após a construção de um banco de dados, procedeu-se uma análise exploratória, empregando técnicas de estatística descritiva. O quadro a seguir mostra os resultados obtidos.

Quadro 2 - Questões objetivas - Respostas dos professores e alunos em percentuais

\begin{tabular}{|c|c|c|c|c|c|c|c|c|c|c|}
\hline \multicolumn{10}{|c|}{ PROFESSORES } \\
\hline Questão & $\mathbf{1}$ & $\mathbf{2}$ & $\mathbf{3}$ & $\mathbf{4}$ & $\mathbf{5}$ & $\mathbf{6}$ & $\mathbf{7}$ & $\mathbf{8}$ & $\mathbf{9}$ & $\mathbf{1 0}$ \\
\hline Sim & 40 & 100 & 60 & 80 & 80 & 100 & 80 & 80 & 100 & 100 \\
\hline Melhorar & 60 & 0 & 40 & 20 & 20 & 0 & 20 & 0 & 0 & 0 \\
\hline Não & 0 & 0 & 0 & 0 & 0 & 0 & 0 & 20 & 0 & 0 \\
\hline Não Sabe & 0 & 0 & 0 & 0 & 0 & 0 & 0 & 0 & 0 & 0 \\
\hline \multicolumn{10}{|c|}{ ALUNOS } \\
\hline Sim & 80,4 & 76,1 & 56,5 & 76,1 & 82,6 & 82,6 & 67,4 & 58,7 & 69,6 & 82,6 \\
\hline Melhorar & 13,0 & 10,9 & 34,8 & 15,2 & 10,9 & 13,0 & 15,2 & 10,9 & 17,4 & 8,7 \\
\hline Não & 4,3 & 8,7 & 6,5 & 6,5 & 2,2 & 2,2 & 6,5 & 26,1 & 4,3 & 2,2 \\
\hline Não Sabe & 2,2 & 4,3 & 2,2 & 2,2 & 4,3 & 2,2 & 10,9 & 4,3 & 8,7 & 6,5 \\
\hline
\end{tabular}

Analisando os dados podemos perceber que os professores têm uma visão positiva do seu trabalho, acreditam estarem preocupados com a aprendizagem, com a postura ativa do aluno e as demandas próprias da EAD. Por outro lado, em parte, mostram-se inseguros e abertos a possibilidades de melhora em suas atividades. Podemos, também, perceber que as questões com as quais os professores não se mostram tão seguros são as que se referem aos aspectos afetivos dos alunos e na construção dos valores nas atividades propostas.

Com o objetivo de aprimorar a análise, considerou-se que as respostas SIM representavam a percepção do indicador, e as respostas DEVE MELHORAR e NÃO significavam que aquele indicador não estava sendo bem percebido ou não existia. Procedeu-se o cruzamento dos dados dos alunos e dos professores, tendo por objetivo identificar semelhanças e diferenças entre os dois grupos. Para cada variável, foram agrupadas as respostas SIM, separadamente por aluno e por professor, calculando-se as freqüências absolutas e percentuais. Após, comparou-se os dois grupos pela prova estatística "Quiquadrado de Pearson” (Quadro 3), encontrando-se evidências de diferença significativa apenas entre as distribuições das respostas da questão número 1 (na apresentação dos conteúdos, incentiva(o) os alunos a pesquisarem e contribuírem 
com a turma).

Quadro 3 - Respostas de professores e alunos, comparadas com Quiquadrado de Pearson

\begin{tabular}{|c|c|c|c|}
\hline Questão & $\chi^{2}$ & df & valor $\mathbf{~}$ \\
\hline $\mathbf{1}$ & 4,675 & 1 & 0,031 \\
\hline $\mathbf{2}$ & 1,253 & 1 & 0,263 \\
\hline $\mathbf{3}$ & 0,009 & 1 & 0,924 \\
\hline $\mathbf{4}$ & 0,013 & 1 & 0,909 \\
\hline $\mathbf{5}$ & 0,148 & 1 & 0,700 \\
\hline $\mathbf{6}$ & 0,904 & 1 & 0,342 \\
\hline $\mathbf{7}$ & 0,047 & 1 & 0,828 \\
\hline $\mathbf{8}$ & 0,671 & 1 & 0,413 \\
\hline $\mathbf{9}$ & 1,512 & 1 & 0,219 \\
\hline $\mathbf{1 0}$ & 0,649 & 1 & 0,420 \\
\hline
\end{tabular}

Estes resultados foram confirmados por uma técnica de análise multivariada, denominada análise de correspondência. As proporções de resposta SIM nas dez questões foram plotadas em um diagrama de dispersão, apresentado na figura a seguir. Este gráfico sugere a existência de uma correlação positiva entre respostas de alunos e professores. A análise foi complementada pelo cálculo do coeficiente de correlação de Pearson, encontrando-se $\mathrm{r}=0,622$ (valor $\mathrm{p}=0,031$ ), indicando que existe uma "tendência para", ou seja, nas questões em que se verificou um maior percentual de resposta SIM de professores, houve, também, um maior percentual de respostas SIM de alunos.

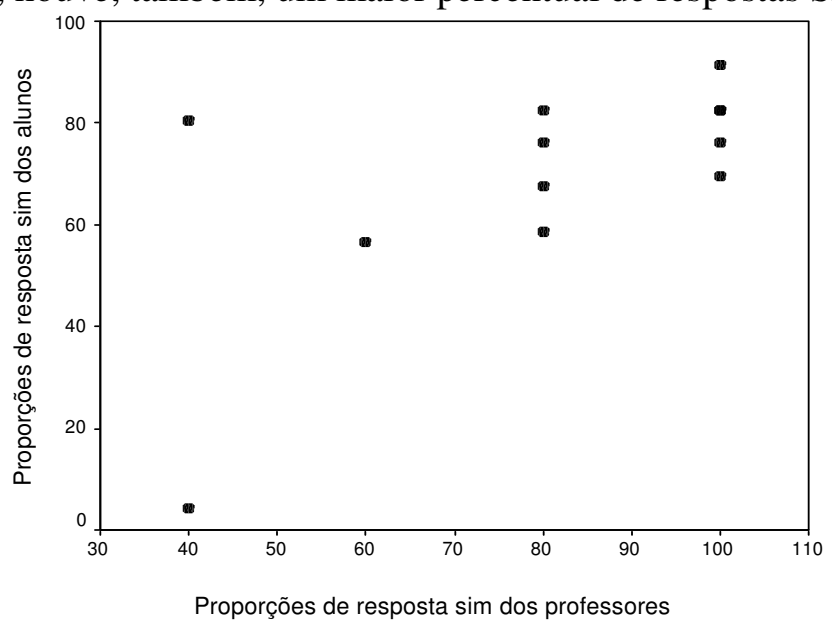

Figura 1: Diagrama de Dispersão das proporções de resposta sim de professores e alunos

A figura anterior evidencia que a maior diferença de proporções de resposta SIM acontece apenas na questão 1, mas mostra, também, que no contexto geral professores e alunos estão de acordo com os saberes envolvidos na prática de EAD realizadas.

Para complementar a análise quantitativa, os dados referentes às respostas de professores às outras seis questões discursivas foram analisados de acordo com o processo de redução, como descrito por Miles e Huberman (1994). Ao final do processo de redução das respostas dos professores, se obteve os seguintes dados:

Quadro 4 - Respostas dos Professores - questões discursivas após processo de redução

11) Se você for novamente professor na modalidade EAD, o que você mudaria?

Maior interação. Maior cooperação. Organizaria melhor o material.

Conheceria melhor as ferramentas . Revisaria a avaliação
Categorias iniciais Interação

Cooperação

Pedagógica/Comunicacional Técnica 


\begin{tabular}{|c|c|}
\hline $\begin{array}{l}\text { 12) Nessa experiência diferenciada de ensino aprendizagem, como você se sentiu como } \\
\text { professor? } \\
\text { Muito bem/sem surpresas. Repensando a relação professor-aluno. Repensando o conceito } \\
\text { ensino-aprendizagem. Desafiado. Frustrado. Com uma responsabilidade enorme.Com falta } \\
\text { de experiência.Sobrecarregado. }\end{array}$ & $\begin{array}{c}\text { Pedagógica } \\
\text { Responsabilidade (Ética) } \\
\text { Gestão do Tempo }\end{array}$ \\
\hline $\begin{array}{l}\text { 13) Quais foram suas principais aprendizagens? } \\
\text { Uso das ferramentas virtuais. Deve-se planejar bem o conteúdo e o material a ser } \\
\text { disponibilizado. Existe uma pedagogia diferenciada para a EAD. Deve-se colocar a agenda } \\
\text { de atividades com maior frequêencia. A maioria dos alunos não é autônoma }\end{array}$ & $\begin{array}{c}\text { Técnica } \\
\text { Pedagógica/Comunicacional } \\
\text { Ética }\end{array}$ \\
\hline $\begin{array}{l}\text { 14) Quais foram suas maiores dificuldades? } \\
\text { Dificuldades dos Professores que foram colocadas nos alunos. Fazer o aluno entender que a } \\
\text { freqüência é dada pela participação constante. Fazer o aluno entender que EAD não é moleza } \\
\text { Dificuldades dos Professores que foram colocadas neles mesmos. Acompanhar } \\
\text { continuamente cada aluno. Compreender o mecanismo de funcionamento da EAD }\end{array}$ & $\begin{array}{l}\text { Interação/Comunicacional } \\
\text { Pedagógica } \\
\text { Ética/Gestão do Tempo } \\
\text { Técnica/Pedagógica }\end{array}$ \\
\hline $\begin{array}{l}\text { 16) Você acredita que ações de solidariedade na modalidade EAD podem ser } \\
\text { desenvolvidas? Como? } \\
\text { Listas de discussão (mas presencial é melhor). Realizando atividades interativas (com o } \\
\text { Wiki, por exemplo) MAS problemas como tempo. Os próprios alunos partilhando } \\
\text { conhecimentos, idéias, com o uso do fórum de discussão. Orientações colocadas no Material } \\
\text { de Apoio que incentivem o compartilhamento de descobertas, material, dicas,...Estimular } \\
\text { maior interação entre os alunos, atividades mais partilhadas. }\end{array}$ & $\begin{array}{l}\text { Interação/Gestão do Tempo } \\
\text { Cooperação/Interação }\end{array}$ \\
\hline
\end{tabular}

Refletindo sobre as respostas dadas pelos professores, pôde-se perceber que, de forma geral, eles sentiram dificuldades de ordem técnica, pedagógica, comunicacional e de gestão do tempo, além de terem se dado conta de que poderiam trabalhar mais as questões de interação e cooperação. Estas respostas remetem a questões como o ineditismo da situação e suas conseqüências em termos de desestruturação: novos questionamentos, centrações, necessidade de novas criações, novas aprendizagens, interesse em saber da possibilidade de aplicar essas novas aprendizagens em outras situações, bem na direção de ruptura, conforme Cunha $(1996,1998,2006)$ e de virtualização de Levy (1997). As respostas à pergunta 13 (Quais foram suas principais aprendizagens?) demonstram que houve esta necessidade: "existe uma pedagogia diferenciada em EAD", "deve-se planejar melhor o conteúdo e o material a ser disponibilizado", "deve-se colocar a agenda com mais frequiência". Da mesma forma, as respostas à pergunta 15 (Existem aprendizagens realizadas a partir dessa experiência na modalidade EAD que poderão modificar sua atuação como professor nas aulas presenciais?) demonstram que os professores questionaram sua atuação nas aulas presenciais e vêem essas aprendizagens do ambiente virtual como possíveis de serem incorporadas em sua prática docente, independentemente da modalidade.

Quando perguntados sobre a possibilidade de desenvolver ações solidárias em EAD, dois professores responderam que sentiam falta de condições ideais. Segundo eles, as ações poderiam ser desenvolvidas, mas no presencial seria melhor e, ainda, alegaram falta de tempo. As respostas que condicionam a realização de ações de solidariedade a determinadas situações podem sugerir, como em outros estudos (Santos, 2002; Cunha, 1996; Moraes, 2002), a existência desse tipo de conhecimento em patamar inferior ao último, quando a solidariedade torna-se um imperativo radical. Ou ainda, podem sugerir que, embora esse conhecimento esteja em patamares superiores, as condições de contexto individual ou/e coletivo impedem sua ação, salientando que "poder ser solidário" vincula-se a condições complexas e dinâmicas. Da mesma forma, os professores que responderam ser possível haver ações de solidariedade em EAD com "os próprios alunos partilhando conhecimentos, idéias, com o uso de fóruns de discussão", ou ainda "estimulando maior interação", ou "compartilhando descobertas, material, dicas", expuseram, apenas, os aspectos de interação e partilha desse conhecimento. Tais colocações parecem sugerir que desconhecem sua complexidade, 
evidenciando que esse conhecimento, como outros, dependem de um processo de aprendizado longo e laborioso.

\section{Conclusões}

As posições dos professores, cotejadas com o referencial teórico trabalhado, induziram à revisão das categorias iniciais, que foram sistematizadas de outra forma. Com intenção de responder às perguntas dessa investigação, sobre os saberes docentes em EAD na perspectiva do conhecimento-solidariedade, construiu-se, então, o quadro a seguir:

Quadro 5 - Resumo das dimensões dos saberes docentes em EAD

\begin{tabular}{|c|c|}
\hline $\begin{array}{l}\text { Dimensão dos } \\
\text { Saberes Docentes }\end{array}$ & $\begin{array}{c}\text { Dimensão } 2 \\
\text { Condições que favorecem ações na perspectiva do conhecimento-solidariedade }\end{array}$ \\
\hline \multirow[t]{7}{*}{ Pedagógica } & Paradigma Emergente \\
\hline & Concepção de conhecimento construtivista \\
\hline & Pedagogia Relacional \\
\hline & Pensamento divergente, complexo, flexível \\
\hline & $\begin{array}{l}\text { Uso da possibilidade de grande produção escrita e de exigência de maior organização de } \\
\text { pensamento, aumento de auto-estima, responsabilidade, prazer e entusiasmo. }\end{array}$ \\
\hline & $\begin{array}{l}\text { Uso da capacidade de concretude e resiliência das informações para obtenção de maior } \\
\text { reciprocidade nas relações e reversilidade de pensamento. }\end{array}$ \\
\hline & $\begin{array}{l}\text { Uso da possibilidade de criação de CVA e de cenários e estratégias para disponibilização e } \\
\text { tratamento dos conteúdos. }\end{array}$ \\
\hline \multirow[t]{2}{*}{ Comunicacional } & Lógica de comunicação aberta, complexa, flexível \\
\hline & $\begin{array}{l}\text { Interatividade, no sentido de disposição interna para grande quantidade de trocas e no sentido } \\
\text { de deixar uma ïndeterminância no ar" que funcione como uma abertura para a co-autoria, } \\
\text { com o objetivo de favorecer a reciprocidade, a tomada de consciências das próprias ações, } \\
\text { objetividade e a criatividade. }\end{array}$ \\
\hline Técnica & Familiaridade com o uso de recursos informáticos incluindo TIC e AVA. \\
\hline \multirow[t]{2}{*}{ Gestão } & Gestão do tempo \\
\hline & Gestão dos recursos informáticos-comunicacionais \\
\hline \multirow[t]{3}{*}{ Ética } & Saber ser solidário \\
\hline & Querer ser solidário \\
\hline & Poder ser solidário \\
\hline
\end{tabular}

Através dos indicadores elaborados em função das dificuldades e facilidades apontadas na pesquisa realizada esperamos contribuir nas práticas de educação a distância no que tange a incorporação de outros paradigmas que se ocupem de uma visão integral dos processos de ensino e de aprendizagem. Acreditamos na perspectiva do conhecimento-solidariedade como uma possibilidade de superação do paradigma dominante, bem como na instauração de práticas inovadoras que contemplem os múltiplos saberes docentes que investigamos. O ineditismo da modalidade a distância exige do professor novas construções teóricas e práticas que necessitam constante formação, como em todo processo educativo. Todavia, a formação permanente colocase como condição necessária, pois pode permitir a exploração das ferramentas digitais na construção de outros saberes, além dos técnicos, tais como a ética, o respeito mútuo e a própria solidariedade.

\section{Referências Bibliográficas}

ANDRÉ, Marli; LÜDKE, Menga. Pesquisa em Educação: abordagens qualitativas. São Paulo: EPU, 1986.

CUNHA Maria Isabel da. O Professor Universitário na transição de paradigmas. Campinas, SP: Papirus, 1998.

. Relação Ensino e Pesquisa. In: VEIGA, Ilma Passos Alencastro (org.).

Didática: o ensino e suas relações. Campinas, SP: Papirus, 1996.

. Aprendizagens significativas na formação inicial de professores: um estudo no 
espaço dos Cursos de Licenciatura. Interface: Comunicação, Saúde e Educação, v.5, n.9, p.103116, 2001. Disponível em http://www.interface.org.br/revista9/artigo1.pdf

- Maria Isabel da (org.). Formatos Avaliativos e concepção de docência. Campinas, SP: Autores Associados, 2005.

LEVY, Pierre. O que é virtual? São Paulo: Ed. 34, 1997.

LUCARELLI, Elisa. Teoria y Practica como innovación em docencia, investigación y actualización pedagógica. Cuadernos de Investigación. Buenos Aires, Argentina: Instituto de Ciencias de la Educación, Faculdad de FIlosofia y Letras, Universidad de Buenos Aires, 1994.

MILES, M. B. \& HUBERMANN, A. M. Qualitative data analysis. Los Angeles: Sage, 1994.

MORAES, Maria Cândida. Tecendo a rede, mas com que paradigma? In:

Educação a distância: fundamentos e práticas. Campinas, SP, UNICAMP/NIED, 2002. MORIN, Edgar. Educar na era planetária: o pensamento complexo como Método de aprendizagem no erro e na incerteza humana. São Paulo: Cortez Editora, 2003.

SANTOS, Boaventura de Souza. A crítica da razão indolente: contra o desperdício da experiência. São Paulo: Cortez, 2002. 